\title{
Virologic and immunologic outcome of HAART in Human Immunodeficiency Virus (HIV)-1 infected patients with and without tuberculosis (TB) and latent TB infection (LTBI) in Addis Ababa, Ethiopia
}

Desta Kassa ${ }^{1,2^{*}}$, Gebremedhin Gebremichael $^{1}$, Yodit Alemayehu', Dawit Wolday ${ }^{3}$, Tsehaynesh Messele ${ }^{1}$ and Debbie van Baarle ${ }^{2}$

\begin{abstract}
Background: HIV/TB coinfection remains a major challenge even after the initiation of HAART. Little is known about Mycobacterium tuberculosis (Mtb) specific immune restoration in relation to immunologic and virologic outcomes after long-term HAART during co-infections with latent and active TB.

Methods: A total of 232 adults, including 59 HIV patients with clinical TB (HIV + TB+), 125 HIV patients without clinical TB (HIV + TB-), 13 HIV negative active TB patients (HIV-TB+), and 10 HIV negative Tuberculin Skin TST positive (HIV-TST+), and 25 HIV-TST- individuals were recruited. HAART was initiated in $113 \mathrm{HIV}+$ patients (28 TB + and 85 TB-), and anti-TB treatment for all TB cases. CD4+ T-cell count, HIV RNA load, and IFN- $\gamma$ responses to ESAT-6/ CFP-10 were measured at baseline, 6 months (M6), 18 months (M18) and 24 months (M24) after HAART initiation.

Results: The majority of HIV + TB- $(70 \%, 81 \%, 84 \%)$ as well as HIV + TB + patients $(60 \%, 77 \%, 80 \%)$ had virologic success (HIV RNA < 50 copies/ml) by M6, M18 and M24, respectively. HAART also significantly increased CD4+ T-cell

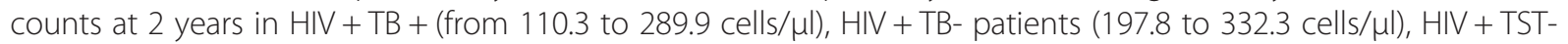

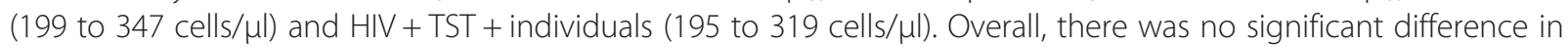
the percentage of patients that achieved virologic success and in total CD4+ counts increased between HIV patients with and without TB or LTBI. The Mtb specific IFN- $\gamma$ response at baseline was significantly lower in HIV + TB + $(3.6 \mathrm{pg} / \mathrm{ml})$ compared to HIV-TB + patients $(34.4 \mathrm{pg} / \mathrm{ml})$ and HIV + TST + $(46.3 \mathrm{pg} / \mathrm{ml})$ individuals; and in HIV-TB + patients compared to HIV-TST + individuals $(491.2 \mathrm{pg} / \mathrm{ml})$. By M18 on HAART, the IFN- $\gamma$ response remained impaired in HIV + TB + patients $(18.1 \mathrm{pg} / \mathrm{ml}$ ) while it normalized in HIV + TST + individuals (from 46.3 to $414.2 \mathrm{pg} / \mathrm{ml}$ ).

Conclusions: Our data show that clinical and latent TB infections do not influence virologic and immunologic outcomes of ART in HIV patients. Despite this, HAART was unable to restore optimal TB responsiveness as measured by Mtb specific IFN- $\gamma$ response in HIV/TB patients. Improvement of Mtb-specific immune restoration should be the focus of future therapeutic strategies.
\end{abstract}

Keywords: HIV, Tuberculosis, HAART

\footnotetext{
* Correspondence: dkassa2003@gmail.com

${ }^{1}$ Infectious and non-infectious diseases research directorate, Ethiopian Health and Nutrition Research Institute (EHNRI), P.O. Box 1242, Addis Ababa,

Ethiopia

${ }^{2}$ Department of Internal Medicine and Infectious Diseases and Department of Immunology, University Medical Center Utrecht, Utrecht, The Netherlands Full list of author information is available at the end of the article
} 


\section{Background}

Human immunodeficiency virus/Acquired immunodeficiency syndrome (HIV/AIDS) associated morbidity and mortality has reduced substantially since the introduction of Highly Active Antiretroviral Therapy (HAART) in the mid 90's [1,2]. Access to Antiretroviral Therapy (ART) in low and middle income countries has been expanded following the launche of " 3 by 5 " global initiative [3], though only $54 \%$ of those eligible for ART were on treatment by 2011 [2]. In Ethiopia, where free ART was started in 2005, >250,000 ( 79\%) of the adults requiring ART were actually treated [4].

The primary goal of HAART is to suppress HIV-1 RNA lower than the detection level (LDL) of the assay within 3 to 6 months on treatment and restore immunologic function, to reduce morbidity and mortality, to reduce vertical transmission, and improve quality of life [5]. However, there are still un-resolved problems including early mortality [6], incomplete responses [7], variations in HAART outcomes [8], lack of universal consensus to define treatment failures and time to start ART [9], drug resistance [10] and lost to follow-ups [7].

While HIV RNA testing is the golden standard to monitor patients on ART [8], due to costs and technical demands of the HIV RNA test, CD4+ T cell measurements are recommended for resource poor settings [11]. Immunologic parameters, however, have lower performance to identify virologic failures which could lead to premature change or to continuous use of failed regimens reviewed in [12]. This leads to higher morbidity and mortality rates and more complex resistance in settings where virologic tests are not available [13]. Therefore, accurate diagnosis of treatment failure is necessary in settings where free ART service is accelerating and patient monitoring is exclusively dependent on clinical and $\mathrm{CD} 4+\mathrm{T}$ cell measurements like in Ethiopia.

Furthermore, despite that HAART has significantly reduced morbidity and mortality in HIV/TB patients [14], studies showed defects of immune response in HIV/TB patients on HAART including suboptimal restoration of $\mathrm{CD} 4+\mathrm{T}$ cells in number, phenotype and function $[15,16]$, and incomplete TB specific immune restoration [17]. Higher TB incidence in individuals on continuous HAART as compared to the HIV negative local population, which could be due to incomplete immune restoration specific to $\mathrm{TB}$, was also reported [18]. However, data regarding the magnitude of immune restoration specific to $M t b$ in relation to $\mathrm{CD} 4+$ and virologic responses to long-term HAART in patients with TB and LTBI is limited.

Overall, although extensive studies aiming to evaluate ART outcomes have been performed, the studies are predominantly from developed countries, and they are different in study design, ex-/inclusion criteria, ethnicity,
ART experience, ARV regimen, duration, and definitions, which makes it difficult to generalize HAART outcomes in different countries [19]. Especially in Ethiopia, like in many HIV/TB endemic settings, little data is available $[20,21]$ regarding HAART outcome in patients with and without active TB and LTBI.

In summary, these studies strongly support the need of recent data from well defined longitudinal cohort studies on HAART, which is crucial to provide answers and insights to the HAART related challenges and develop and update national ART guidelines [19,22].

The aim of this observational cohort study which comprised three clinical groups including HIV + TB+, HIV + TB-, and HIV-TB + patients, and two control groups including HIV-TST+, and HIV-TST- individuals, was to evaluate the long-term outcome of HAART by comprehensively measuring key parameters including mortality, virologic and immunologic responses, and $M t b$ specific immune restoration by measuring IFN $-\gamma$ production in response to Early Secretory Antigenic Target-6/Culture Filtrate Protein-10 (ESAT-6/CFP-10).

\section{Results}

\section{Characteristics of the study population at enrolment}

Demographic, clinical and laboratory data of the study populations at baseline are shown in Table 1. A total of 232 participants were included. Thirteen HIV-TB+, 59 HIV + TB+, 125 HIV + TB- (of whom 43 were HIV + TST+, and 82 HIV + TST-), 10 HIV-TST+, and 25 Controls (HIV-TST-) were enrolled. HIV + TB + patients had lower numbers of CD4+ T cells ( $p=0.003)$, total Lymphocyte count $(\mathrm{TLC})(\mathrm{p}=0.001)$, Hemoglobin $(\mathrm{Hgb})(\mathrm{g} / \mathrm{dl})$ $(\mathrm{p}=0.02)$, Body Mass Index (BMI) $\left(\mathrm{Kg} / \mathrm{m}^{2}\right)(\mathrm{p}=0.002)$, CD4\% $(p=0.006)$, but higher HIV RNA levels $(p=0.02)$ than HIV + TB- patients. There was no significant difference in CD4+, TLC, Hgb, BMI, CD4\% and HIV RNA tests between HIV + TST- and HIV + TST + individuals (data not shown). Of special interest, $10(6.3 \%)$ of the ART naïve HIV patients had HIV RNA $<50$ copies/ml (LDL) at enrolment. The mean CD4+ T cell count of these subjects was 476.1 ( $\mathrm{SD} \pm 260.7$ cells $/ \mu \mathrm{l})$.

At enrolment, more than $50 \%$ of the HIV + TB + patients had advanced diseases stages (anemic, malnourished, WHO stages 3 plus 4 , and immunosuppressed) while only $15-36 \%$ of the HIV + TB- patients had these advanced disease stages. There was also a higher percentage of chronic hepatitis $B$ virus coinfection in the HIV + TB + patients, (19.3\%), followed by the HIV + TB-, (7.2\%), and healthy controls (4.2\%) (Table 1 ).

\section{Outcome of HAART}

\section{ART initiation, mortality and follow-up status}

A total of 113 (61.4\%) HIV patients including 28 HIV + $\mathrm{TB}+$ and $85 \mathrm{HIV}+\mathrm{TB}$ - [of whom 31 were HIV + TST + 
Table 1 Baseline characteristics of the study populations $(n=232)$

\begin{tabular}{|c|c|c|c|c|c|}
\hline & $\begin{array}{l}\text { HIV + TB+ } \\
(n=59)\end{array}$ & $\begin{array}{l}\text { HIV + TB- } \\
(n=125)\end{array}$ & $\begin{array}{l}\text { HIV-TB+ } \\
(n=13)\end{array}$ & $\begin{array}{l}\text { HIV-TST+ } \\
(n=10)\end{array}$ & $\begin{array}{l}\text { HIV-TST } \\
(n=25)\end{array}$ \\
\hline \multicolumn{6}{|l|}{ Demographic data } \\
\hline Age, years & $33.1 \pm 8.7$ & $33.2 \pm 7.3$ & $28.5 \pm 9.5^{b}$ & $26.6 \pm 7.4$ & $24.6 \pm 6.6$ \\
\hline Female, n (\%) & $28(47.5)$ & $83(66.4)$ & $6(46.2)$ & $6(60)$ & $16(64)$ \\
\hline \multicolumn{6}{|l|}{ Clinical data } \\
\hline CHBV coinfection, n (\%) & 11/57 (19.3) & $8 / 112(7.2)$ & $3(15)$ & $2(20)$ & $1(4)$ \\
\hline \multicolumn{6}{|l|}{ WHO stage, n (\%) } \\
\hline $1+\|$ & $3 / 50(6)$ & $80(64)$ & & & \\
\hline$I I I+I V$ & $47 / 50(94)$ & $45(36)$ & NA & NA & NA \\
\hline $\mathrm{BMl}, \mathrm{kg} / \mathrm{m} 2$ & $18.9 \pm 3.1^{\mathrm{a}}$ & $21.3 \pm 3.5$ & $18.9 \pm 2.8$ & $21.4 \pm 2.5$ & $21.4 \pm 2.0$ \\
\hline $\mathrm{BMI}<18.50$ kg/m², n (\%) & $29(49.2)$ & 18/124 (14.6) & $6(46)$ & $8(80)$ & $24(96)$ \\
\hline \multicolumn{6}{|l|}{ Laboratory data } \\
\hline $\mathrm{Hgb}, \mathrm{g} / \mathrm{dl}$ & $12.2 \pm 3.7^{\mathrm{a}}$ & $13.2 \pm 2.5$ & $13.5 \pm 2.5^{b}$ & $16.4 \pm 1.8^{c}$ & $18.0 \pm 2.1$ \\
\hline $\mathrm{Hgb}<12 \mathrm{~g} / \mathrm{dl}$ (anemic), n (\%) & 23/43 (53.5) & 29/107 (27.1) & $2(23)$ & 0 & 0 \\
\hline CD4+ count $/ \mu l$ & $173.7 \pm 180.8^{a}$ & $279.2 \pm 212.4$ & $478.1 \pm 253^{b}$ & $787.3 \pm 274$ & $754.8 \pm 241$ \\
\hline \multicolumn{6}{|l|}{ CD4+ category, n (\%) } \\
\hline$<100$ & $27(48.2)$ & $26(22.2)$ & $1(1.7)$ & 0 & 0 \\
\hline $100-200$ & $12(21.4)$ & $26(22.2)$ & $6(10.0)$ & 0 & 0 \\
\hline$>=201$ & $17(30.3)$ & 65 (55.6) & $53(88.3)$ & $10(100)$ & $25(100)$ \\
\hline TLC & $1175 \pm 754^{a}$ & $1626 \pm 750$ & $1485 \pm 895^{b}$ & $1975 \pm 1483$ & $1.668 \pm 559$ \\
\hline HIV RNA (log10copies/ml) & $4.5 \pm 0.8^{a}$ & $4.1 \pm 0.9$ & NA & NA & NA \\
\hline \multicolumn{6}{|l|}{ HIV RNA category, n (\%) } \\
\hline LDL & $1(2.2)$ & $9(8.0)$ & & & \\
\hline$<=100000$ & $14(30.4)$ & $97(85.8)$ & & & \\
\hline$>100000$ & $32(69.6)$ & $16(14.2)$ & NA & NA & NA \\
\hline
\end{tabular}

Data are means \pm standard deviations (SD) unless stated; $n$ (\%) Number of patients, CHBV chronic Hepatitis B Virus, defined as the presence of hepatitis surface antigen (HBsAg) in the plasma, BMI Body mass index, Hgb Hemoglobin, TLC total lymphocyte, HIV RNA plasma viral load, LDL lower than detection limit (HIV RNA $<50$ copies/ml), WHO World Health Organization, NA: not applicable.

${ }^{a}$ Comparing HIV $+\mathrm{TB}+$ and HIV $+\mathrm{TB}-; P<0.05$

${ }^{b}$ Comparing HIV + TB + and HIV-TB $+; P<0.05$.

${ }^{c}$ Comparing HIV-TST + and HIV-TST- ; $P<0.05$.

and 54 were HIV+TST-], initiated ART and were followed for a median of 23.9 (IQR 22.5-24.4) months. The majority $(78 \%)$ of the HIV + TB- patients received $\mathrm{D} 4 \mathrm{~T}+3 \mathrm{TC}+\mathrm{NVP}$ HAART regimens. At ART initiation, $\mathrm{HIV}+\mathrm{TB}+$ patients had lower mean $\mathrm{CD} 4+\mathrm{T}$ cells $(p=0.005), \mathrm{CD} 4 \%(p=0.03)$, TLC $(\mathrm{p}=008)$, and BMI $(p<0.0001)$ than HIV + TB- patients (Table 2$)$.

At 2 years, $18(9.8 \%)$ patients died of which $63 \%$ within the first 24 weeks. The risk factors for early mortality in the HIV patients with and without TB were advanced disease stages including baseline $\mathrm{CD} 4+$ count $<100$ cells $/ \mu$ l (OR: 5.7, 95\% CI $1.8-17.2, p=0.03$ ), WHO-stages III plus IV (OR: 4.8 95\% CI 1.3-17.5, $p=0.01$ ), and $\mathrm{BMI}<18.5 \mathrm{~kg} / \mathrm{m} 2$ (OR: $1.295 \%$ CI 0.37-3.8, $p=0.77$ ) (data not shown).

Overall, at M6, M18 and M24 of follow-up time, 21/59 (35.6\%), 21/51 (41.2\%) and 23/41 (56.1) of the HIV +
TB + patients; and 27/125 (21.6\%), 36/120 (30\%) and 43/ $115(37.4 \%)$ of the HIV + TB- patients, respectively, were lost to follow-up (more than 60 days late for a scheduled date of clinic visit).

\section{Virologic outcomes}

We measured virologic outcomes by determining the HIV RNA level as well as the proportion of patients with virologic success. In both $\mathrm{HIV}+\mathrm{TB}+$ and $\mathrm{HIV}+\mathrm{TB}-$ patients, the mean HIV RNA level significantly declined after HAART ( $<<0.05$ and $\mathrm{p}<0.001$, respectively) (Figure 1A). There was no significant difference in mean HIV RNA decline between patients with and without TB or LTBI (Figure 1A \& B).

By M24 on HAART, the majority of the individuals $(>80 \%)$ achieved virologic success (HIV RNA $<50$ copies $/ \mathrm{ml}$ ). There was no significant difference in the 
Table 2 Therapeutic, clinical and immunovirologic characteristic of the study participants at ART initiation $(n=113)$

\begin{tabular}{|c|c|c|c|}
\hline & $\mathrm{HIV}+\mathrm{TB}+$ & HIV + TB- & $p$ value \\
\hline No of patients initiated ART & 28 & 85 & \\
\hline \multicolumn{4}{|l|}{ Demographic } \\
\hline Female, n (\%) & $14(50)$ & $56(65.7)$ & \\
\hline Age, years & $34.1 \pm 8.3$ & $34.4 \pm 7.7$ & \\
\hline \multicolumn{4}{|l|}{ Treatment } \\
\hline Mean follow-up days before ART initiation & 78.7 & 37.7 & \\
\hline Mean delay in commencing HAART following TB treatment, days & 100 & & \\
\hline \multicolumn{4}{|l|}{ HAART regimen at ART initiation, $\mathrm{n}(\%)$} \\
\hline D4T/3TC/NVP & $4(15)$ & $66(78)$ & \\
\hline D4T/3TC/EVZ & $11(41)$ & $2(2)$ & \\
\hline AZT/3TC/NVP & $7(26)$ & $12(14)$ & \\
\hline AZT/3TC/EVZ & $5(16)$ & $4(5)$ & \\
\hline Others & & $1(1)$ & \\
\hline Cortimoxzole treatment, $\mathrm{n}(\%)$ & $15(83.3 \%)$ & $58(59.2 \%)$ & \\
\hline \multicolumn{4}{|l|}{ BMI and Laboratory values at ART initiation } \\
\hline $\mathrm{BMI}\left(\mathrm{kg} / \mathrm{m}^{2}\right)$ & $18.1 \pm 2.5$ & $21.3 \pm 3.7$ & 0.0001 \\
\hline CD4+ (cells/ $\mu l)$ & $110.3 \pm 71.3$ & $197.8 \pm 153.2$ & 0.005 \\
\hline CD4\% & $10.1 \pm 5.3$ & $14.6 \pm 9.9$ & 0.033 \\
\hline TLC (cells/ $\mu \mathrm{l})$ & $1078 \pm 512$ & $1521 \pm 692$ & 0.007 \\
\hline $\mathrm{Hgb}(\mathrm{g} / \mathrm{dl})$ & $13.4 \pm 3.4$ & $13.0 \pm 2.5$ & 0.68 \\
\hline HIV RNA (log $\log _{10}$ Copies/ml) & $4.3 \pm 0.9$ & $4.3 \pm 0.9$ & 0.73 \\
\hline \multicolumn{4}{|l|}{ Follow-up outcomes } \\
\hline Deaths, n (\%) & $8 / 59(13.6)$ & $10 / 125(8.0 \%)$ & \\
\hline
\end{tabular}

Data in mean \pm standard deviation (SD) unless stated; $n$ number of patients, D4T Stavudine, 3TC lamividine, NVP Nevirapine, EVZ Efavirenz, AZT Zidovudin, BMI Body mass index, Hgb Hemoglobin, TLC total lymphocyte count; M6, M18 and M24 =6, 18 and 24 months after HAART initiation.

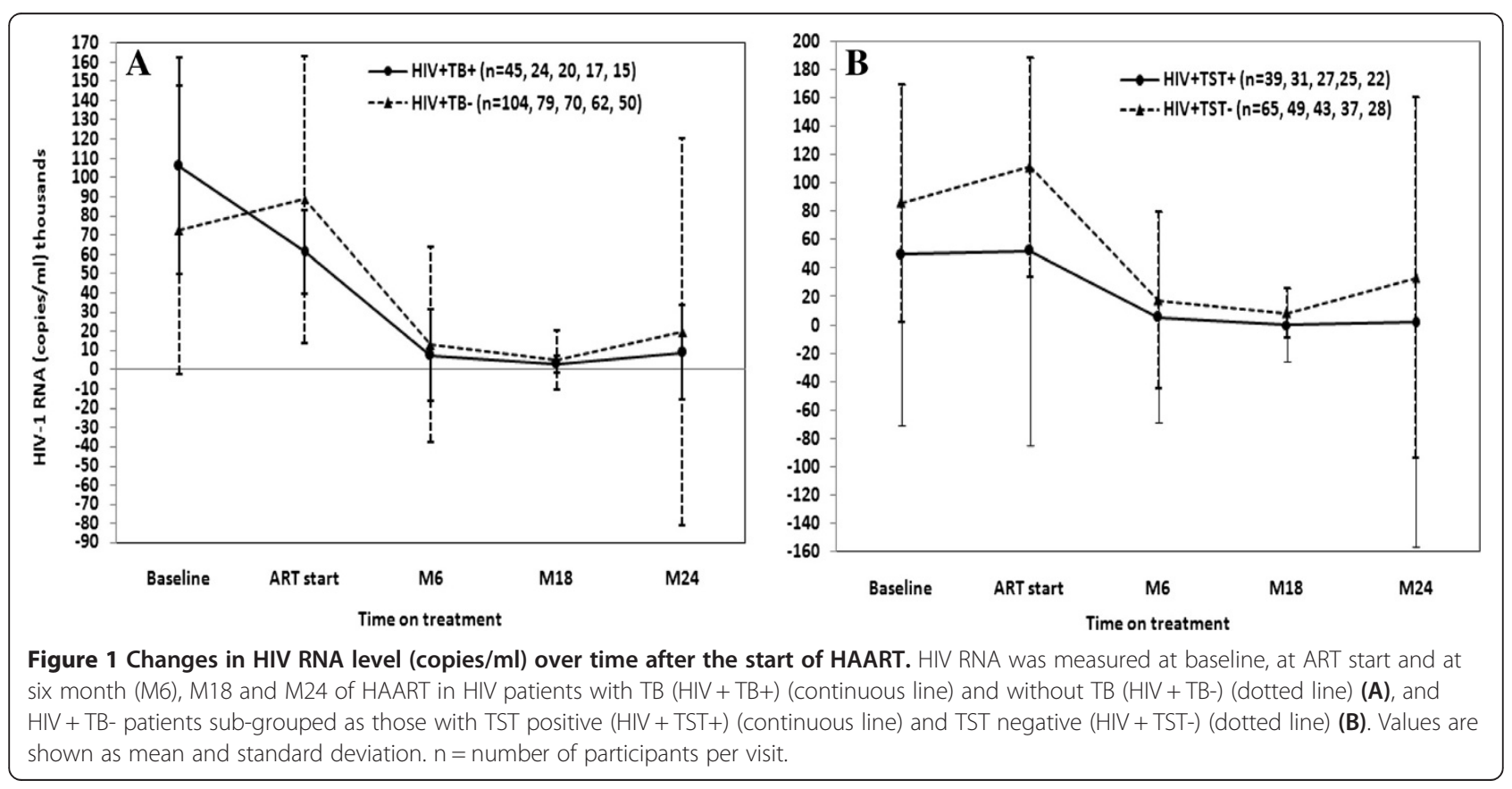


proportion of patients achieving virologic success between individuals with and without TB or LTBI (Figure 2A \& B). Moreover, whereas 28 (85\%) of the patients on HAART maintained HIV RNA $<50$ copies/ml at M6, M18 and M24 (ever suppressed), 5 (15\%) never reached HIV RNA $<50$ copies/ml (never suppressed).

At M6, 13 (19\%) HIV + TB- patients had virologic failure (HIV RNA >5000 copies/ml), for which baseline $\mathrm{BMI}<18.5 \mathrm{~kg} / \mathrm{m}^{2}, \mathrm{CD} 4+$ count $<100$ cells $/ \mu \mathrm{l}$, and WHO stages 3 and 4 [OR: 3.8, 2.3, 4.9; $p=0.05,0.32,0.02$, respectively] were risk factors. Other factors like sex (OR: 0.51) age (OR: 0.41), Hgb (OR: 0.19), and HIV RNA (OR: 0.89) were not associated with the risk of virologic failures (Table 3).

\section{Immunologic responses}

Quantitative restoration of CD4+ cells is one of the principal evidences for immune recovery during HAART. There was a significant increase in CD4+ T cell count at M6, M18 and M24 of HAART in both the HIV + TB$(P<0.001$ for all $)$ as well as the $\mathrm{HIV}+\mathrm{TB}+$ patients $(\mathrm{p}=0.02,0.001,0.001$, respectively); and in the HIV + TST $+(p=0.03,003,0.04$, respectively $)$ as well as in the HIV + TST- $(P<0.001$ for all) (Figure 3A \& B).

There was no significant difference in the total CD4+ T cells reached by M6, M18 and M24 in HIV + TB + vs. $\mathrm{HIV}+\mathrm{TB}-(p=0.37,0.63$ and 0.56 , respectively) and in $\mathrm{HIV}+\mathrm{TST}+\mathrm{vs}$. HIV + TST- $(p=0.77,0.62$, and 0.74 , respectively) (Figure 3A \& B). Interestingly, although the study population was small, HIV/TB patients coinfected with HBV $(n=9)$ showed the least increase in CD4+ T cells (Figure $3 \mathrm{~A}$ ).
There was an overall increase in CD4+ count over the two years with an average increase of 6.7 cells/ $\mu$ l per month in the HIV + TB- patients, and 5.9 cells/ $\mu$ l per month in the HIV + TB+. CD4+ increase was highest in the first six months. Despite lower CD4+ T cell count at ART initiation in HIV + TB + patients $(110 \mathrm{CD} 4+$ cell $/ \mu \mathrm{l})$ than $\mathrm{HIV}+\mathrm{TB}$ - patients $(198 \mathrm{CD} 4+\mathrm{cell} / \mu \mathrm{l})(\mathrm{p}=0.001)$, there was no significant difference in the net increase of CD4+ T cells per month as well as in the total CD4+ cells achieved at each time point between the patients with and without TB.

Overall, at two years on HAART, the total CD4+ cells in all clinical groups was still lower by more than two fold compared to healthy controls (HIV-TST-) (771 CD4+ cells/ $\mu$ l) (Figure 3A and B). Moreover, the proportion of patients that attained the critical CD4+ count of $\geq 200$ cells/ $\mu \mathrm{l}$ by two years on ART was 19 (68\%) for HIV + TB-, and $8(73 \%)$ for the HIV + TB+. Six $(21 \%)$ of the HIV + TB- but none of the $\mathrm{HIV}+\mathrm{TB}+$ patients had CD4+ count $>500$ cells $/ \mu$ l (super responders).

At M6, M18 and M24 of HAART, 45\%, 30\%, 42\% of the HIV + TB- and 54\%, 43\%, and 30\% of the HIV + TB + patients, respectively, were diagnosed with immunologic failure (an increase of less than 50 cells/ $\mu$ l by M6, and less than 100 cells/ $\mu$ l by M18 and M24 of HAART). The risk factors for immunologic failure at M6 of HAART for the HIV + TB- patients were WHO stages $3+4$ [OR: 4.3, $\mathrm{p}=0.01$ ], and CD4 $+<100$ cells/ $\mu \mathrm{l}$ ) [OR: $5.6, \mathrm{p}=0.008$ ] at baseline (Table 3).

As shown in Figure 4, for the HIV + TB- patients on ART, the CD4+ increase was steeper in women, in patients with older age, patients with baseline HIV RNA $<10000$
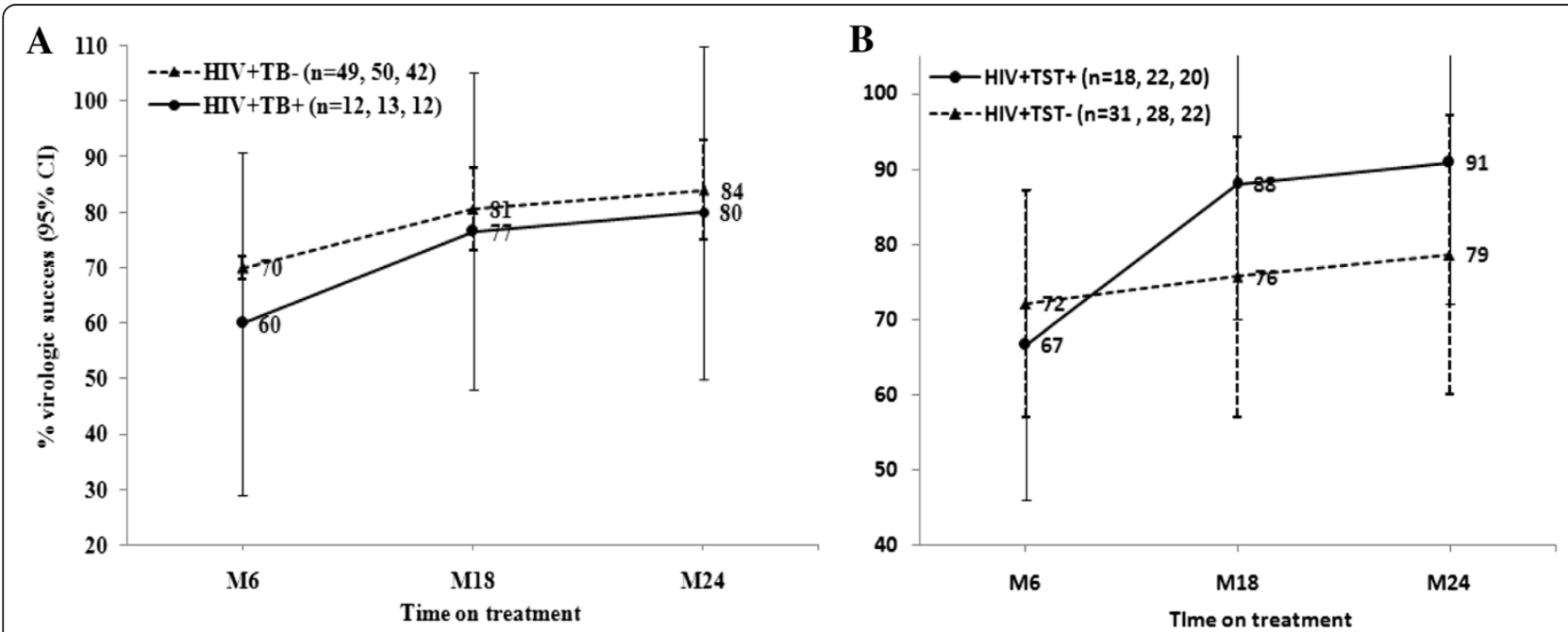

Figure 2 Percentages of patients with virologic success (plasma HIV RNA $<50$ copies/ml) with $95 \%$ confidence interval ( $95 \% \mathrm{CI}$ ) overtime on HAART. HIV RNA was measured at six month (M6), M18 and M24 of treatment in HIV patients with TB (HIV + TB+) (continuous line) and without TB (HIV + TB- (dotted line) (A), and HIV + TB- patients sub-grouped as those with TST positive (HIV + TST+) (continuous line) and TST negative (HIV + TST-) (dotted line) (B). Percentage of patients with virologic success per follow up visit are shown on the line graphs; $n=$ number of participants per visit. 
Table 3 Logistic regression analysis showing odds ratio for factors associated with the risk of immunologic and virologic failures of the HIV patients with no TB (HIV + TB-) at six months of ART

\begin{tabular}{|c|c|c|c|c|c|c|}
\hline & \multicolumn{3}{|c|}{$\begin{array}{c}\text { Risk of immunologic failure } \\
\text { (an increase of CD4+<50 cells/ } \mu \mathrm{l}) \\
\text { at } 6 \text { months }(n=56)\end{array}$} & \multicolumn{3}{|c|}{ 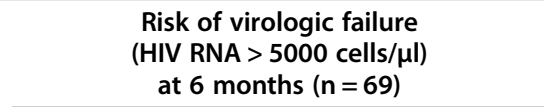 } \\
\hline & OR & $95 \% \mathrm{Cl}$ & $P$ value & OR & $95 \% \mathrm{Cl}$ & $P$ value \\
\hline \multicolumn{7}{|l|}{ Sex } \\
\hline Male & 1 & & & 1 & & \\
\hline Female & 0.62 & $1.0-1.9$ & 0.40 & 0.51 & $0.12-2.1$ & 0.93 \\
\hline \multicolumn{7}{|l|}{ Age (years) } \\
\hline $36-60$ & 1 & & & 1 & & \\
\hline $16-35$ & 0.65 & $0.21-2.0$ & 0.44 & 0.41 & $0.10-1.7$ & 0.21 \\
\hline \multicolumn{7}{|l|}{ BMI } \\
\hline$<18.50$ & 1 & & & 1 & & \\
\hline$>=18.50$ & 0.90 & $0.25-3.29$ & 0.87 & 3.75 & $1.0-14.4$ & 0.05 \\
\hline \multicolumn{7}{|l|}{$\mathrm{Hgb}$} \\
\hline$<12$ & 1 & & & 1 & & \\
\hline$>=12$ & 0.38 & $0.08-1.7$ & 0.21 & 0.19 & $0.02-1.6$ & 0.13 \\
\hline \multicolumn{7}{|l|}{ CD4+ count $/ \mu \mathrm{l}$} \\
\hline$>=100$ & 1 & & & 1 & & \\
\hline$<100$ & 5.6 & $1.6-20.1$ & 0.008 & 2.3 & $0.45-11.2$ & 0.32 \\
\hline$>=200$ & 1 & & & 1 & & \\
\hline$>200$ & 0.22 & $0.07-0.73$ & 0.01 & 0.89 & $0.24-3.2$ & 0.85 \\
\hline \multicolumn{7}{|c|}{ HIV RNA copies/ml } \\
\hline$>=100000$ & 1 & & & 1 & & \\
\hline$<100000$ & 1.2 & $0.3-5.3$ & 0.82 & 0.38 & $0.04-3.3$ & 0.4 \\
\hline \multicolumn{7}{|l|}{ WHO stages } \\
\hline$I+\|$ & 1 & & & 1 & & \\
\hline$I I I+I V$ & 4.3 & $1.4-13.4$ & 0.01 & 4.9 & $1.2-19.9$ & 0.02 \\
\hline \multicolumn{7}{|l|}{ TB coinfection } \\
\hline No & 1 & & & 1 & & \\
\hline Yes & 1.4 & $0.4-1.8$ & 0.5 & 0.23 & $0.03-1.9$ & 0.17 \\
\hline
\end{tabular}

OR Odds ratio, $95 \% \mathrm{Cl} 95 \%$ confidence Interval; $\mathrm{n}=$ total number of participants who have CD4+ count and plasma HIV RNA measurement at 6 month of HAART.

copies/ml, and CD4+ count $>200$ cells $/ \mu$ l with the difference becoming larger over time. More interestingly, the total CD4+ T cell count achieved in the HIV + TB- patients started ART at CD4+>200, was two fold higher than those started ART at $<200$ cells $/ \mu$ l (495.0 vs. 243.2 cells $/ \mu$, respectively, $(P=0.007)$. This indicated that advanced pre-treatment immunodeficiency is the most important factor for diminished restoration of CD4 cell counts after HAART.

Mtb antigen specific IFN- $\gamma$ response before and after HAART Although quantitative measurement of $\mathrm{CD} 4+$ counts and HIV RNA level provides a general insight in immune recovery, measuring qualitative restoration of $\mathrm{TB}$ specific immune responses will provide insight whether antigen specific immune responses are also restored.
Therefore, we measured Mtb antigen (ESAT-6/CFP-10) specific IFN- $\gamma$ responses during HAART (Figure 5). Compared to IFN- $\gamma$ response in LTBI individuals (HIV-TST + ) $(491.2 \mathrm{pg} / \mathrm{ml})$ at baseline, there was significantly lower IFN- $\gamma$ production in $\mathrm{HIV}+\mathrm{TB}+(3.6 \mathrm{pg} / \mathrm{ml})(p=0.004)$, in HIV-TB + $(34.4 \mathrm{pg} / \mathrm{ml})(p=0.004)$, and in HIV + TST + $(46.3 \mathrm{pg} / \mathrm{ml})$ patients $(p=0.002)$. Moreover, IFN- $\gamma$ production at baseline was significantly lower in HIV + $\mathrm{TB}+$ compared to HIV-TB + $(p=0.02)$ and HIV + TST + $(p=0.04)$ patients, and in HIV + TST + compared to HIV$\mathrm{TB}+(p=0.004)$.

In the HIV + TST + individuals, following initiation of HAART, although the level of IFN- $\gamma$ did not change by M6 $(44.3 \mathrm{pg} / \mathrm{ml})$, it increased sharply after that and normalized by M18 of treatment $(414.2 \mathrm{pg} / \mathrm{ml})$ $(p=0.007)$ and reached similar level as HIV-TST + 

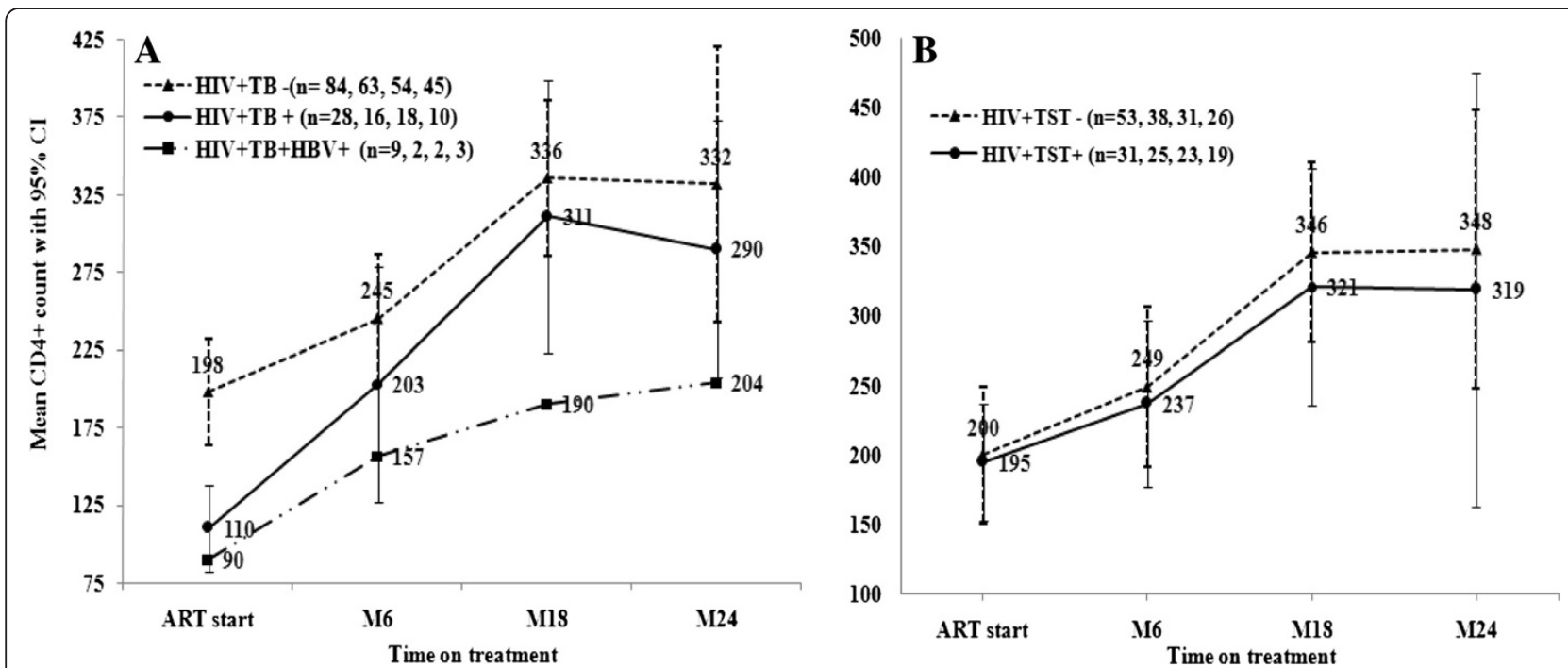

Figure 3 Mean CD4+ count increase (cells/ $\mu$ l) with $95 \%$ Confidence interval $(95 \% \mathrm{Cl}$ ) over time after the start of HAART. CD4+ T cell count was measured at ART start, six month (M6), M18, and M24 of HAART in HIV patients with TB (HIV + TB+) (continuous line), with no TB (HIV + TB-) (dotted line), and HIV patients with TB and HBV (HIV + TB + HBV) (dash line) (A), and HIV + TB- patients sub-grouped as those with TST positive (HIV + TST+) (continuous line) and those TST negative (HIV + TST-) (dash line) (B). Number of CD4+ T cell counts per follow-up visit are shown on the line graphs; $n=$ number of participants per visit.

individuals $(491.2 \mathrm{pg} / \mathrm{ml})(\mathrm{p}>0.05)$. In contrast, there was no significant increase in $M t b$ specific immunity for the HIV patients with TB (HIV + TB+) on TB treatment and on HAART by M6 $(31.7 \mathrm{pg} / \mathrm{ml})$ as well as by M18 $(18.1 \mathrm{pg} / \mathrm{ml})$ of treatment. For the HIV negative $\mathrm{TB}$ patients $(\mathrm{HIV}-\mathrm{TB}+)$ on $\mathrm{TB}$ treatment, mean IFN- $\gamma$ production significantly increased by M6 $(181 \mathrm{pg} / \mathrm{ml})$ $(\mathrm{p}=0.005)$

To see whether the poor $M t b$-specific recovery is due to lower $\mathrm{CD} 4$ recovery, we correlated the increase in CD4+ cell count in the HIV + TB + patients after HAART with IFN- $\gamma$ production upon stimulation with ESAT-6/
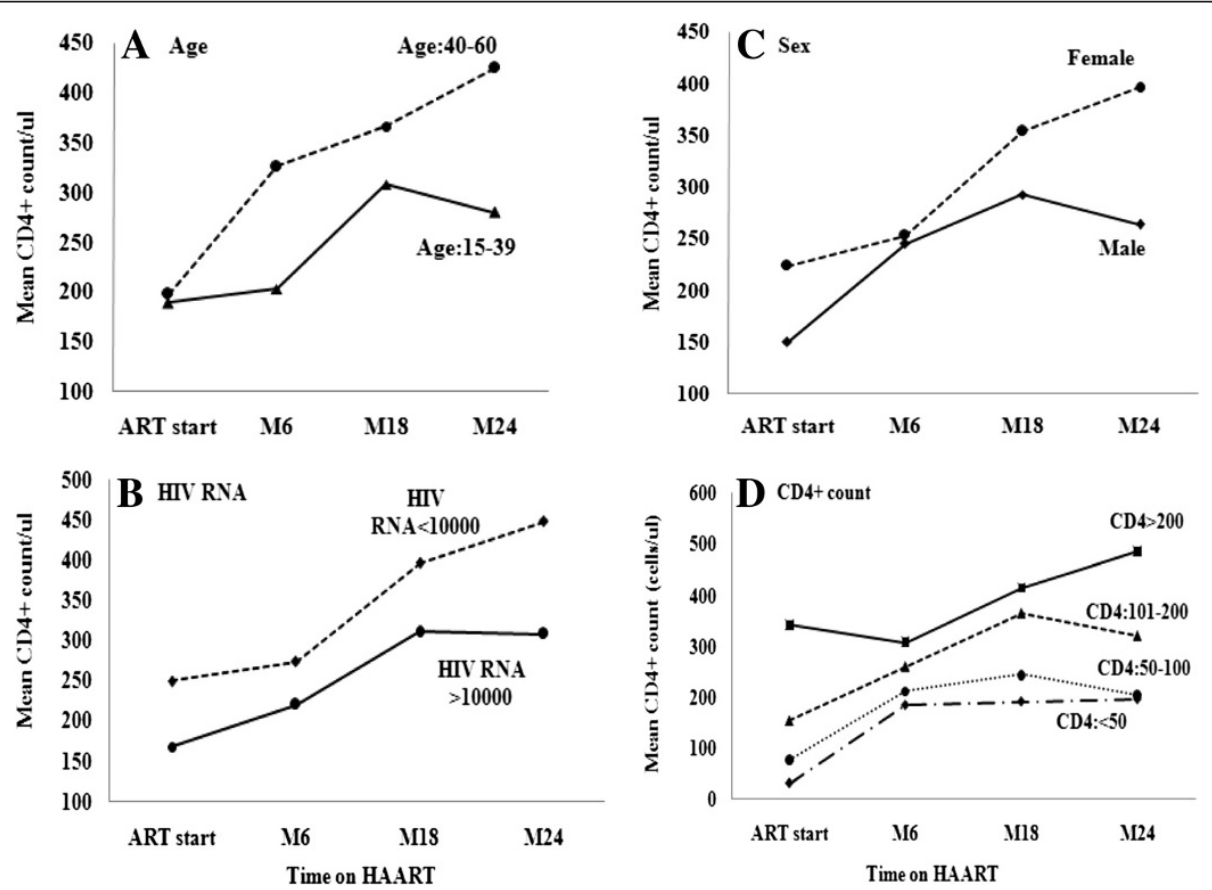

Figure 4 Mean CD4+ count increase (cells/ $\mu$ l) over time after the start of HAART in HIV patients with no TB (HIV + TB-) according to the baseline category of (A) Age, (B) HIV RNA (copies/ml), (C) Sex, and (D) CD4+ count (cells/ $\mu$ l). 


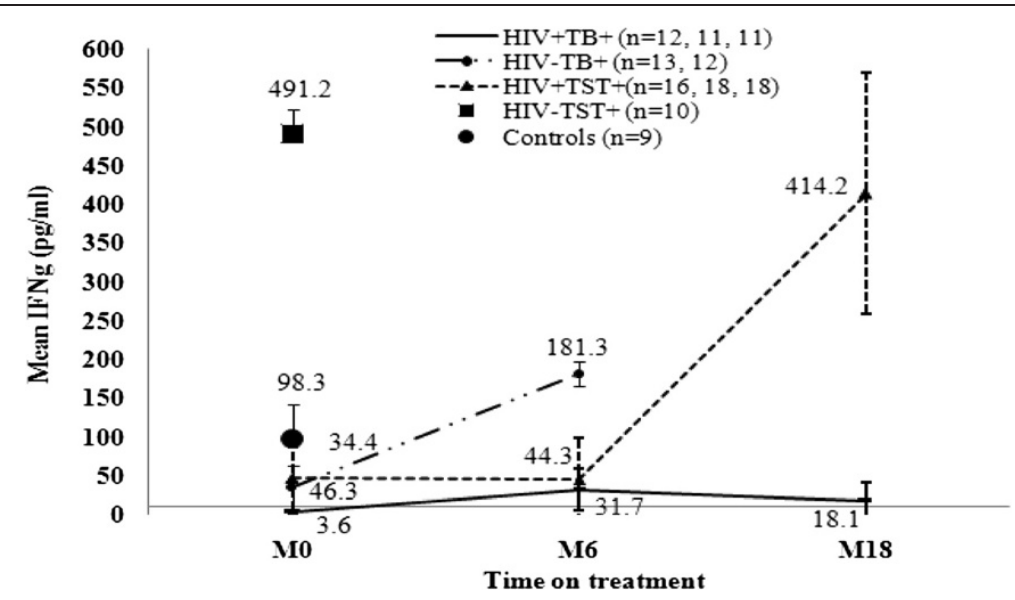

Figure 5 Restoration of $M t b$ specific IFN- $\gamma(\mathrm{pg} / \mathrm{ml}$ ) response overtime after the start of HAART and TB treatment. Level of IFN- $(\mathrm{pg} / \mathrm{ml})$ was measured at baseline (M0), and at six (M6) and M18 of treatment in 7th day culture supernatants of whole blood stimulated with Mtb specific (ESAT-6/CFP-10) antigen. HIV + TB+: HIV patients with TB (continuous line); HIV-TB: HIV negative TB patients (long-dash line); HIV + TST+: HIV positive tuberculin skin test (TST) positive patients (dot line); HIV-TST+: HIV negative TST positive individuals (square dot); and Controls (HIV-TST-) (circle dot). Mean of IFN- $\gamma$ (pg/ml) with standard deviation per follow-up visit are shown on the line graph; $n=$ number of participants per visit shown on the legend.

CFP-10 (immune function specific to TB). No significant correlation between CD4+ T cell count recovery and IFN$\gamma$ production was found $(r=0.19, p=0.40, n=22)$. In contrast, however, there was a strong positive correlation between the recovery of CD4+ cells and IFN- $\gamma$ production in the HIV negative active TB patients (HIV-TB+) following TB treatment for six months $(r=0.71, p=0.0007$, $n=19$ ) (Figure 6).

\section{Discussions}

In this study, we determined the long-term outcome of HAART in HIV patients with and without TB and LTBI by comprehensively measuring HIV RNA suppression, CD4+ T-cell recovery, and immune reconstitution specific to $M t b$.
The goal of ART is to suppress HIV-1 RNA below the detection limit of the assay within 12-24 weeks [5], or to less than $0 \cdot 5-0 \cdot 75 \log$ copies/ml by 4 weeks [23]. In this study, $84 \%$ of the non-TB patients on HAART had HIV RNA $<50$ copies/ml at 24 months on ART. This is comparable to most studies from Africa [24,25], Europe [15,26], and United States [27].

Nevertheless, $19 \%$ of the non-TB patients in this study were virologic failures (HIV RNA > 5000 copies/ml) at 6 months of ART. Reports from Cameroon [28] and Brazil [29] also showed virologic failure (HIV RNA $>400$ copies/ml) in $13 \%$ and $28 \%$ of patients at 6 months on ART. As reported by Tuboi SH et al. [29], malnutrition and advanced WHO stages were risk factors for virologic failure in this study, which strongly indicate the
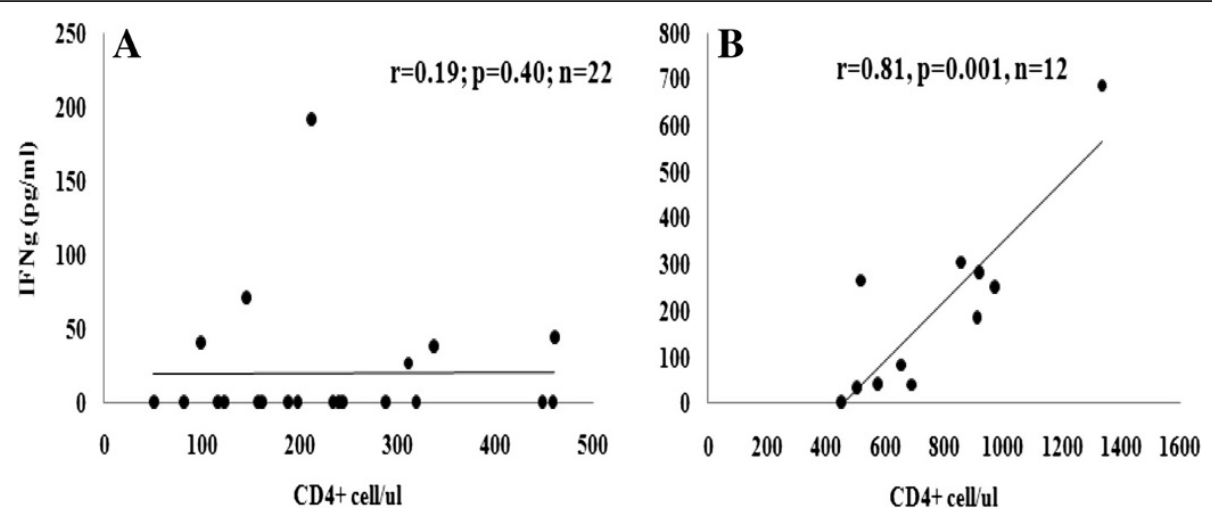

Figure 6 Spearman correlation between IFN- $\gamma$ production and absolute CD4+ count recovery after the start of HAART and TB treatment. (A) HIV positive patients with active TB (HIV + TB+) at 6th and 18th months of HAART and TB treatment, and (B) HIV negative TB patients (HIV-TB+) at six months of TB treatment. IFN- $\gamma$ secretion was measured in 7th day culture supernatants of whole blood stimulated with Mtb specific antigen (ESAT-6/CFP-10). $r=$ correlation coefficient. 
need of earlier identification of eligible patients and earlier initiation of HAART for better treatment outcome.

Interestingly, comparable to other reports [15,30], also $80 \%$ of the HIV patients with TB in this study had HIV RNA $<50$ copies/ml at 24 months on HAART, which is similar to viral suppression in patients without TB (Figures $1 \& 2$ ) and has been reported recently in another study [31]. In contrast, others have reported a high hazard ratio for virologic failure in patients with TB on ART [32].

Since many patients in Sub-Saharan Africa present to the health facilities with advanced disease stages and low CD4 cell counts [24], they may have limited advantage for CD4+ recovery after ART [17]. However, despite the overall lower baseline CD4+ count of the healthy Ethiopians [33], and the lower CD4+ count at ART start (197 cells/ $\mu \mathrm{l}$ ) in HIV patients without TB in this study, the increase in CD4+ cells after two years on ART (332 cells/ $\mu \mathrm{l}$ ) was comparable with a recent report from Ethiopia [34], and other reports from Africa [24], in lowincome countries (Africa, Latin America and Asia) [35], and the United States $[27,36]$. The mean CD4+ increase by 24 month on ART in this study (6.7 cells $/ \mu \mathrm{l} / \mathrm{month}$ ) was also comparable to a report from South Africa [37].

However, $45 \%$ of the non-TB patients in this study had immunologic failure (an increase of $<50 \mathrm{CD} 4+$ cells $/ \mu \mathrm{l}$ ) at 6 months, while $32 \%$ failed to restore CD4+ T cell count to $\geq 200$ cells $/ \mu$ l by 2 years on ART, which is similar to a study from Nigeria [38]. Similar to Lifson et al. [36], advance WHO stages and lower CD4+ count at baseline were risk factors for immunologic failure, which strongly suggests the need for earlier identification of eligible patients and initiation of HAART.

Furthermore, since more than $50 \%$ of the HIV/TB patients in Sub-Saharan Africa presented to the health facilities at advanced disease stages and start ART at CD4+ counts of 100-150 cells/ $\mu \mathrm{l}[16,24]$ the benefit of patients on ART could be limited [28,39]. More than $50 \%$ of the HIV/TB patients in our cohort had advanced disease stage at enrolment and the CD4+ count at ART initiation was 110 cells/ $\mu$ l (Table 2). Interestingly, however, we observed no difference in the CD4+ cell increase over time on HAART in patients with and without TB as reported by Lawn SD et al. [40] and Dronda F et al. [31]. In contrast, others reported reduced $\mathrm{CD} 4+$ recovery after ART in patients with TB $[15,41,42]$. Interestingly, although the study sample was small, we did observe reduced CD4+ recovery in HIV/TB patients co-infected with HBV (Figure 3A) as reported by Pe' rez-Molina JA et al. [43].

Overall, the total CD4+ count achieved by 2 years on HAART in patients with TB $(290$ cells $/ \mu \mathrm{l})$ and without TB (332 cells $/ \mu \mathrm{l})$ in this study was comparable to findings from African and other developed countries, although it was still lower compared to the healthy Ethiopian populations $(754.8$ cells $/ \mu \mathrm{l})$. This poses the question whether immune function is restored after 2 year of HAART. Therefore, the $M t b$ specific immune restoration after 18 month on HAART was investigated.

It has been estimated that, if HAART is accessible to all patients with $\mathrm{CD} 4+<200$ cells $/ \mu \mathrm{l}$ and would restore optimal immune responses specific to $M t b$, the cumulative incidence of TB would decrease by $22 \%$ over 20 years [44]. However, if immune restoration to $M t b$ is incomplete, there would be a substantial number of patients on HAART which are continuously at high risk for TB. In this study we measured the level of IFN- $\gamma$, a cytokine which plays a key role in the control of $M t b$ infection [45] in response to $M t b$ specific antigen (ESAT-6/CFP-10) [46].

We observed lower IFN- $\gamma$ secretion in HIV negative TB patients compared to LTBI individuals at baseline as reported by Hanna LE et al. [47]. Coinfection with HIV severely decreased the secretion of IFN- $\gamma$ in both groups. Furthermore, in support to previous reports $[41,42,48]$, IFN- $\gamma$ production after 18 month of HAART was not restored in HIV patients with TB while it was normalized in those with LTBI. Among the possible factors contributing to the impaired IFN- $\gamma$ response in the HIV/TB patients are exhaustion of immune system [47] defined as a reduced proliferation of immune cells and impaired cytokine production due to infection with HIV [49] and $M t b$ [50], and depletion of Mtb specific CD4+ cells due to direct infection with HIV [15]. Our observation that there was no correlation between $\mathrm{CD} 4+$ count recovery after HAART and level of IFN- $\gamma$ production in the HIV + $\mathrm{TB}+$ patients, unlike to that of HIV-TB + patients where there was a strong correlation between $\mathrm{CD} 4+\mathrm{T}$ cell recovery and IFN- $\gamma$ production following TB treatment (Figure 5), suggests that other factors may play a role in the impaired functional recovery of $M t b$ specific immune responses in the $\mathrm{HIV}+\mathrm{TB}+$ patients. Among the strategies proposed to boost immune restoration specific to TB after HAART are early initiation of HAART and isoniazid prophylaxis, and adjunctives such as BCG vaccination or co-administration of IL-2 [48,51].

Overall, addressing the long-term outcome of HAART by comprehensively measuring the key parameters of ART responses in a well defined cohort of patients with and without active TB and LTBI is the major strength of this study. The study addressed immune responses after HAART not only by measuring the absolute CD4+ cell recovery as a proxy for immune restoration but also by measuring IFN- $\gamma$ response specific to $M t b$. However, the fact that there is no golden standard definition of LTBI could be counted as limitations of the study

\section{Conclusions}

In this observational cohort study, we showed sustained outcomes of long-term HAART in HIV patients with 
and without TB and LTBI as evidenced by clinical, immunologic and virologic data. Advanced pre-ART disease stages were the risk factors for diminished CD4+ and virologic responses to HAART and high mortality, which strongly indicated the need of early identification of eligible patients and early access to care and treatment. Mtb specific immune reconstitution in HIV/TB patients remained impaired after 18 months on HAART, which suggested the need of strong prevention, earlier diagnosis, and treatment of TB, as well as earlier initiation of HAART. Factors contributing to impaired $M t b$ specific immune restoration in HIV/TB patients after HAART need to be investigated in order to develop intervention methods which could boost the immune response. In addition, we should do further study on the immunological mechanisms associated with HIV/ TB coinfection.

\section{Materials and methods}

\section{Study populations and settings}

This observational cohort study was performed from April 2007-February 2011 at St Peter Specialized Referral TB Hospital, Akaki and Kality Health centers in Addis Ababa, Ethiopia. Adults of both sexes who were naïve to ART and TB treatment were enrolled after informed and written consent was sought.

Diagnosis of active tuberculosis (TB) was based on both clinical and bacteriological evidences. At least two sputum smears stained by the Ziehil-Neelsen direct method were required to be microscopy positive for Acid Fast Bacilli (AFB) [52]. Except for TB patients, Mantoux Tuberculin Skin Testing (TST) for tuberculin was done for all participants. A diameter of skin induration with $\geq 10 \mathrm{~mm}$ in HIV un-infected, and $\geq 5 \mathrm{~mm}$ in HIVinfected individuals was graded as TST positive (TST + ), and was considered as a LTBI [52].

The study participants were enrolled in 5 clinical groups: HIV patients with TB (HIV + TB+), and without TB (HIV + TB-) [sub-grouped further as Tuberculin Skin Test (TST) positive (HIV + TST + ) and TST negative HIV + TST-], HIV negative TB cases (HIV-TB+), HIVTST + , and controls (HIV-TST-). After enrolment, the $\mathrm{HIV}+\mathrm{TB}+, \mathrm{HIV}+\mathrm{TB}-$, and HIV-TB + groups were scheduled for follow-up (FU) clinic visits at sixth month (M6), M18 and M24.

At enrolment and during FU visit, each participant was interviewed using a standard questionnaire and detailed clinical, anthropometric and demographic data were recorded by a clinician or a nurse. A total of $20 \mathrm{ml}$ heparinized venous blood was collected and transported immediately to the National HIV Referral Laboratory (NHL), at EHNRI. HAART was prescribed for eligible HIV patients and anti-TB treatment for all the TB cases free of charge as per the national guidelines. Antibiotic prophylaxis was also prescribed by the physician at enrolment or during the clinic follow-up visits [52].

\section{Laboratory tests}

Laboratory examinations of blood were performed by automated machines following the manufacturer's protocol. Hematological values were determined using Cell Dyn (Abbott laboratories, Abott Par IC Jl 60064, USA); CD4+ $\mathrm{T}$ cell counts were determined using Becton Dickinson (BD) FACSCalibur (Becton Dickinson, San Jose, USA); and Plasma HIV-1 RNA load was measured using the NucliSens EasyQ NASBA diagnostic 2007/1 (Organon, Teknika) which has a detection range of $50-3,000,000$ copies $/ \mathrm{ml}$. The level of IFN- $\gamma(\mathrm{pg} / \mathrm{ml})$ in the 7th day whole blood culture supernatant stimulated with $M t b$ specific antigen (ESAT-6/CFP-10) was measured by xMAP multiplex technology (Luminex, Austin TX, USA), using Biosource reagents (Biosource, Camarillo, USA), and analyzed with the STarStation v2.0 software (Applied Cytometry Systems, United Kingdom) as described previously [53].

\section{Definitions}

Based on data from different studies [54,55], the national [56] and international [11] guidelines, and considering the small sample size in this study, we choose the following cut-off values to define HAART outcomes. Body mass index $(B M I)\left(\mathrm{kg} / \mathrm{m}^{2}\right)$ was categorized as malnutrition $(\mathrm{BMI}<18.50)$ and normal $(18.50 \geq \mathrm{BMI} \leq 24.99)$, and anemia was defined as hemoglobin $(\mathrm{Hgb})<12 \mathrm{~g} / \mathrm{dl}$ [57]; virologic success was defined as achieving a viral suppression (HIV RNA $<50$ copies $/ \mathrm{ml}$, or lower than the detection level (LDL) of the assay) after HAART, and virologic failure as a single HIV RNA $>5000$ copies $/ \mathrm{ml}$ after a minimum of 6 months on HAART [11]. Immunologic success was defined as an increase of $\geq 50 \mathrm{CD} 4+$ cells $/ \mu \mathrm{l}$ at M6 and $\geq 100$ cells $/ \mu \mathrm{l}$ at M18 and M24 from that at ART initiation; immunologic failure as a failure to increase $\geq 50$ cells/ $\mu \mathrm{l}$ at M6, or $\geq 100$ cells/ $\mu \mathrm{l}$ at M18 and M24; and super-responders as patients able to achieve CD4+ count of $>500$ cells $/ \mu \mathrm{l}$ after 2 years of HAART.

\section{Statistical analysis}

Data entered using Microsoft Access (DBse XI) was double-checked for discrepancies. All data analysis was done using Intercooled STATA version 11.0 (College Station, Texas, USA). Descriptive analyses including counts and frequencies for categorical variables, and mean (standard deviation, SD) or median (interquartile range, IQR) for continuous variables were computed. Results were compared using chi-square test and Fisher's exact test for categorical variables and non-parametric tests (Wilcoxon signed rank test and Mann-Whitney U test) for continuous variables. Fixed (sex, groups) and 
time-updated variables (age, CD4+ count, HIV RNA, BMI, Hgb, TLC, co-infections) were included in the logistic regression analysis to identify risk factors for failed immunologic and virologic responses to HAART. A $\mathrm{p}$-value of $<0.05$ was considered as statistical significant.

\section{Ethical approval}

This study was ethically approved institutionally, by the Scientific and Ethics Review Office (SERO), EHNRI; and nationally by the National Health Research Ethics Review Committee (NHRERC), Ethiopian Ministry of Science and Technology Agency (ESTA).

\section{Competing interests}

The authors declare that they have no competing interests.

\section{Authors' contributions \\ DK was a lead author on planning, implementation of the study, data analysis, and writing of the draft, interim and final version of the manuscript; GG and YA participated in different laboratory tests; AA participated in counseling the study participants, filling study questionnaires and sample collection; DW, TE and DB - participated in providing advice and help during data analysis and also offered inputs and recommendations during the draft, interim and final version of the manuscript. All authors have seen and approved the final manuscript.}

\section{Acknowledgements}

This work, which is part of an ongoing longitudinal study entitled "Biomarkers of protective immunity against tuberculosis in the context of Human Immunodeficiency Virus/Acquired immunodeficiency Syndrome (HIV/AIDS) in Africa" [58], was supported by the Bill \& Melinda Gates Foundation through the Grand Challenges in Global Health Initiative, grant no. 37772.

This work has been presented in part to the "Australian HIV/AIDS conference 2012" Melbourne, Australia, October 17-19, 2012 (poster number 311). We would like to thank all patients participating in this cohort study, all the study nurses involved, and the data clerk.

\section{Author details}

'Infectious and non-infectious diseases research directorate, Ethiopian Health and Nutrition Research Institute (EHNRI), P.O. Box 1242, Addis Ababa, Ethiopia. ${ }^{2}$ Department of Internal Medicine and Infectious Diseases and Department of Immunology, University Medical Center Utrecht, Utrecht, The Netherlands. ${ }^{3}$ Medical Biotech Laboratory, Addis Ababa, Ethiopia.

Received: 28 March 2013 Accepted: 2 July 2013

Published: 10 July 2013

\section{References}

1. Palella FJ, Delaney KM, Moorman AC: Declining morbidity and mortality among patients with advanced human immunodeficiency virus infection. N Engl J Med 1998, 38:853-860.

2. Joint United Nations Programme on HIV/AIDS (UNAIDS): Report on the global AIDS epidemic, 2012, "UNAIDS / JC2417E". http://www.unaids.org/en/ media/unaids/contentassets/documents/epidemiology/2012/gr2012/ 20121120 UNAIDS_Global_Report_2012_en.pdf.

3. World Health Organization (WHO): Treating 3 million by 2005: making it happen. The WHO strategy. Geneva, World Health Organization, 2003. http://www.who.int/3by5/publications/documents/isbn9241591129.

4. Federal HIV/AIDS Prevention and Control Office (FHAPCO): Multi-sectoral HIV/AIDS response monitoring and evaluation: Annual report; 2011. http://www.HAPCO.gov.et or http://www.etharc.org.

5. Volberding PA, Deeks SG: Antiretroviral therapy and management of HIV infection. Lancet 2010, 376:49-62.

6. Collazos J, Asensi V, Carton JA: CD4 Responses in the Setting or Suboptimal Virological Responses to Antiretroviral Therapy: Features, Outcomes, and Associated Factors. AIDS Res Hum Retroviruses 2009, 25(7):647-655.
7. Menéndez-Arias L: Molecular basis of human immunodeficiency virus drug resistance: an update. Antiviral Res 2010, 85(1):210-31.

8. Nicastri E, Chiesi A, Angeletti C, Sarmati L, Palmisano L, Geraci A, et al: Italian Antiretroviral Treatment Group (IATG): clinical outcome after 4 years follow-up of HIV-seropositive subjects with incomplete virologic or immunologic response to HAART. J Med Virol 2005, 76:153-60.

9. Carpenter CC, Cooper DA, Fischl MA, Gatell JM, Gazzard BG, Hammer SM, et al: Antiretroviral therapy in adults: updated recommendations of the International AIDS Society-USA Panel. JAMA 2000, 283(3):381-390.

10. Jevtovic D, Salemovic D, Ranin J, Pešic'l, Žerjav S, Djurkovic'-Djakovic O: The dissociation between virological and immunological responses with HAART. Biomed Pharmacother 2005, 59:446-451.

11. WHO: Antiretroviral therapy for HIV infection in adults and adolescents: recommendations for a public health approach; 2010. Revision. http://whqlibdoc.who.int/publications/2010/9789241599764_eng.pdf.

12. Misgena DK: The pattern of immunologic and virologic responses to Highly Active Antiretroviral Treatment (HAART): Does success bring further challenges? Ethiop. J. Health Dev 2011, 25(1):61-70.

13. Gupta RK, Hill A, Sawyer AW, Cozzi-Lepri A, Wyl V, Yerly S, et al: Virological monitoring and resistance to first-line highly active antiretroviral therapy in adults infected with HIV-1 treated under WHO guidelines: a systematic review and meta-analysis. Lancet Infect Dis 2009, 9:409-417.

14. Egger S, Petoumenos K, Kamarulzaman A, Hoy J, Sungkanuparph S, Chuah J, Falster $\mathrm{K}$, et al: Long-Term patterns in CD4 response are determined by an interaction between baseline CD4 cell count, viral load, and time: The Asia Pacific HIV observational database (APHOD). J Acquir Immune Defic Syndr 2009, 50:513-520.

15. Cingolani A, Cozzi Lepri A, Castagna A, Goletti D, De Luca A, Scarpellini P, Fanti I, Antinori A, et al: Impaired CD4 T-Cell Count Response to Combined Antiretroviral Therapy in Antiretroviral-Naive HIV-Infected Patients Presenting With Tuberculosis as AIDS-Defining Condition. Clin Infect Dis 2011, 54:853-61.

16. Lawn SD, Kranzer K, Wood R: Antiretroviral therapy for control of the HIV-associated tuberculosis epidemic in resource-limited settings. Clin Chest Med 2009, 30:685-99.

17. Lederman HM, Williams PL, Wu JW, Evans TG, Cohn SE, McCutchan JA, et al: Incomplete immune reconstitution after initiation of highly active antiretroviral therapy in human immunodeficiency virus-infected patients with severe CD4+ cell depletion. J Infect Dis 2003, 188:1794-1803.

18. Gupta A, Wood R, Kaplan R, Bekker L-G, Lawn SD: Tuberculosis Incidence Rates during 8 Years of Follow-Up of an Antiretroviral Treatment Cohort in South Africa: Comparison with Rates in the Community. PLoS One 2012, 7(3):e34156.

19. Marimoutou $C$, Chêne $G$, Mercié $P$, Neau $D$, Farbos $S$, Morlat $P$, Ceccaldi J, et al: Prognostic factors of combined viral load and CD4+ cell count responses under triple antiretroviral therapy, Aquitaine cohort, 1996-1998. J Acquir Immune Defic Syndr 2001, 27:161-167.

20. Horst R, Collin SM, Ritmeijer K, Bogale A, Davidson Rt N: Concordant HIV Infection and Visceral Leishmaniasis in Ethiopia: The Influence of Antiretroviral Treatment and Other Factors on Outcome. Clin Infect Dis 2008, 46(11):1702-1709.

21. Huruy K, Kassu A, Mulu A, Wondie Y: Immune restoration disease and changes in CD4+ T-cell count in HIV- infected patients during highly active antiretroviral therapy at Zewditu memorial hospital, Addis Ababa, Ethiopia. AIDS Res Ther 2010, 7:46.

22. Sabin CA: Cohort studies: to what extent can they inform treatment guidelines? Curr Opin Infect Dis 2010, 23(1):15-20.

23. US Health and Human Services (UHHS): Guidelines for the use of antiretrovira agents in HIV-infected adults and adolescents. Washington, DC: DHHS; 2001.

24. Hammond R, Harry TC: Efficacy of antiretroviral therapy in Africa: effect on immunological and virological outcome measures - a meta-analysis. Int J STD AIDS 2008, 19:291-296.

25. Bussmann H, Wester CW, Ndwapi N, Grundmann N, Gaolathe T, Puvimanasinghe J, et al: Five-year outcomes of initial patients treated in Botswana's National Antiretroviral Treatment Program. AIDS 2008, 22:2303-2311.

26. Geretti AM, Harrison L, Green H, Sabin C, Hill T, Fearnhill E, et al: Effect of HIV-1 subtype on virologic and immunologic response to starting highly active antiretroviral therapy. Clin Infect Dis 2009, 48(9):1296-305.

27. Marconi VC, Grandits GA, Weintrob AC, Chun H, Landrum ML, Ganesan A, Infectious Disease Clinical Research Program HIV Working Group (IDCRP), 
et al: Outcomes of highly active antiretroviral therapy in the context of universal access to healthcare: the U.S. Military HIV Natural History Study. AIDS Res Ther 2010, 7:14

28. Rougemont M, Stoll BE, Elia N, Ngang P: Antiretroviral treatment adherence and its determinants in Sub-Saharan Africa: a prospective study at Yaounde Central Hospital, Cameroon. AIDS Res Ther 2009, 6:21

29. Tuboi SH, Harrison LH, Sprinz E, Albernaz RK, Schechter M: Predictors of virologic failure in HIV-1-infected patients starting highly active antiretroviral therapy in Porto Alegre, Brazil. J Acquir Immune Defic Syndr 2005, 40:324-8.

30. Zanoni BC, Phungula T, Zanoni HM, France H, Feeney ME: Impact of tuberculosis cotreatment on viral suppression rates among HIV-positive children initiating HAART. AIDS 2011, 25:49-55.

31. Dronda F, Sobrino P, Hernández-Novoa B, Caro-Murillo AM, Montero M, Iribarren JA, et al: Response to HAART in treatment-naive HIV-infected patients with a prior diagnosis of tuberculosis or other opportunistic infections. Curr HIV Res 2011, 9:229-36.

32. Lartey M, Sagoe KW, Yang H, Kenu E, Xexemeku F, Oliver-Commey J, et al: Viral decay rates are similar in HIV-infected patients with and without TB coinfection during treatment with an Efavirenz-based regimen. Clin Infect Dis 2011, 52(4):547-50.

33. Mekonnen Y, Geskus RB, Hendriks JC, Messele T, Borghans J, Miedema F, et al: Low CD4 T cell counts before HIV-1 seroconversion do not affect disease progression in Ethiopian factory workers. J Infect Dis 2005, 192(5):739-748.

34. Assefa Y, Kiflie A, Tekle B, Mariam DH, Laga M, Van Damme W: Effectiveness and acceptability of delivery of antiretroviral treatment in health centres by health officers and nurses in Ethiopia. J Health Serv Res Policy 2012, 17(1):24-9.

35. Nash D, Katyal M, Brinkhof MW, Keiser O, May M, Hughes R, Dabis F, et al: Long-term immunologic response to antiretroviral therapy in lowincome countries: a collaborative analysis of prospective studies. AIDS 2008, 22:2291-2302.

36. Lifson AR, Krantz EM, Eberly LE, Matthew Dolan J, Marconi VC, Weintrob AC: Long-term CD4+ lymphocyte response following HAART initiation in a U. S. Military prospective Cohort. AIDS Res Ther 2011, 8(1):2

37. Julg B, Poole D, Ghebremichael M, Castilla C, Altfeld M, Sunpath $H$, et al: Factors Predicting Discordant Virological and Immunological Responses to Antiretroviral Therapy in HIV-1 Clade C Infected Zulu/Xhosa in South Africa. PLoS One 2012, 7(2):e31161.

38. Rawizza HE, Chaplin B, Meloni ST, Eisen G, Rao T, Sankalé JL, et al: Immunologic Criteria Are Poor Predictors of Virologic Outcome: Implications for HIV Treatment Monitoring in Resource-Limited Settings. Clin Infect Dis 2011, 53(12):1283-90.

39. Sanne IM, Westreich D, Macphail AP, Rubel D, Majuba P, Van Rie A: Long term outcomes of antiretroviral therapy in a large HIV/AIDS care clinic in urban South Africa: a prospective cohort study. J Int AIDS Soc 2009, 12:38.

40. Lawn SD, Myer L, Bekker LG, Wood R: Burden of tuberculosis in an antiretroviral treatment programme in sub-Saharan Africa: impact on treatment outcomes and implications for tuberculosis control. AIDS 2006, 20:1605-12.

41. Elsherbiny D, Ren Y, Mcllleron H, Maartens G, Simonsson US: Population pharmacokinetics of lopinavir in combination with rifampicinbased antitubercular treatment in HIV-infected South African children. Eur J Clin Pharmacol 2010, 66:1017-23.

42. Lazaro E, Coureau G, Guedj J, Blanco P, Pellegrin I, Commenges D, et al: Change in T-lymphocyte count after initiation of highly active antiretroviral therapy in HIV-infected patients with history of Mycobacterium avium complex infection. Antivir Ther 2006, 11(3):343-50

43. Pe' rez-Molina JA, D'az-Mene'ndez M, Plana MN, Zamora J, Lo'pez-Ve'lez R and and Moreno S: Very late initiation of HAART impairs treatment response at 48 and 96 weeks: results from a meta-analysis of randomized clinical trials. J Antimicrob Chemother 2012, 67:312-321.

44. Williams BG, Dye C: Antiretroviral therapy for TB control in the era of HIV/ AIDS. Science 2003, 301:1535-37.

45. Flynn J: Immunology of tuberculosis and implications in vaccine development. Tuberculosis 2004, 4:93-101.

46. Pollock JM, Andersen P: The potential of the ESAT- 6 antigen secreted by virulent mycobacteria for specific diagnosis of tuberculosis. I Infect Dis 1997, 175(5):1251-4
47. Hanna LE, Nayak K, Subramanyam S: Incomplete immunological recovery following anti-tuberculosis treatment in HIV-infected individuals with active tuberculosis. Indian J Med Res 2009, 129(5):548-54

48. Lawn SD, Bekkera L-G, Wood R: How effectively does HAART restore immune responses to Mycobacterium tuberculosis? Implications for tuberculosis control. AIDS 2005, 19:1113-1124.

49. Wherry EJ: T cell exhaustion. Nat Immunol 2011, 12:492e9.

50. Wang $X$, Cao Z, Jiang J, Niu H, Dong M, Tong A, et al: Association of mycobacterial antigen-specific CD4+ memory $T$ cell subsets with outcome of pulmonary tuberculosis. J Infect 2010, 60:133e9.

51. Marchetti G, Franzetti F, Gori A: Partial immune reconstitution following highly active antiretroviral therapy: can adjuvant interleukin-2 fill the gap? J Antimicrob Chemother 2005, 55:401-409.

52. Federal Ministry of Health (FMOH): Manual of Tuberculosis, Leprosy and TB/ HIV prevention and control programme. 3rd edition. Addis Ababa, Ethiopia; 2005. http://www.moh.gov.et/English/Resources/Documents/FMOH_Guidelines forTBL_TB_HIV.pdf.

53. Fulton RJ, McDade RL, Smith PL, Kienker LJ, Kettman JR Jr: Advanced multiplexed analysis with the FlowMetrix system. Clin Chem 1997, 43(9):1749-1756

54. Hammer SM, Eron JJ Jr, Reiss P, Schooley RT, Thompson MA, Walmsley S, Cahn P, Fischl MA, Gatell JM, Hirsch MS, Jacobsen DM, Montaner JS, Richman DD, Yeni PG, Volberding PA: International AIDS Society-USA. Antiretroviral treatment of adult HIV infection: 2008 recommendations of the International AIDS Society-USA panel. JAMA 2008, 6;300(5):555-570.

55. Murphya RA, Sunpathb H, Luc Z, Chelinb N, Losinac E, Gordond M, et al: Outcomes after virologic failure of first-line ART in South Africa. AIDS 2010, 24:1007-1012.

56. Federal Ministry of Health (FMOH)-Federal HIV/AIDS Prevention and Control Office (HAPCO) (FMOH/FHAPCO): Single Point HIV Prevalence Estimate, Addis Ababa, June 2007. http://www.etharc.org/aidsineth/publications/ singlepointprev_2007.pdf.

57. Blanc B, Finch CA, Hallberg L: Nutritional anaemias. Report of a WHO Scientific Group. WHO Tech Rep Ser 1968, 405:1-40.

58. Kaufmann SHE, Parida SK: Tuberculosis in Africa: Learning from Pathogenesis for Biomarker Identification. Cell Host Microbe 2008, 4(3):219-228.

\section{doi:10.1186/1742-6405-10-18}

Cite this article as: Kassa et al:: Virologic and immunologic outcome of HAART in Human Immunodeficiency Virus (HIV)-1 infected patients with and without tuberculosis (TB) and latent TB infection (LTBI) in Addis Ababa, Ethiopia. AIDS Research and Therapy 2013 10:18.

\section{Submit your next manuscript to BioMed Central and take full advantage of:}

- Convenient online submission

- Thorough peer review

- No space constraints or color figure charges

- Immediate publication on acceptance

- Inclusion in PubMed, CAS, Scopus and Google Scholar

- Research which is freely available for redistribution 